Пушкарская Юлия Александровна - стариий преподаватель, Пятигорский медикофармацевтический институт - филиал федерального государственного бюджетного образовательного учреждения высшего образования «Волгоградский государственный медицинский университет» Министерства здравоохранения Российской Федераџии, 357501, Россия, Ставропольский край, 2. Пятигорск, пр. Калинина, дом 11, $\underline{\text { e-mail: }}$ Pushkarskaya_85@mail.ru

Алексанянц Гайк Дереникович - доктор медицинских наук, профессор, Федеральное государственное бюджетное образовательное учреждение высшего образования «Кубанский государственный университет физической культуры, спорта и туризма», 350015, Россия, Краснодарский край, г. Краснодар, ул. имени Буденного, дом 161, е-таil: Alexanyans@mail.ru

Медведева Олеся Андреевна - кандидат биологических наук, доцент, Федеральное государственное бюджетное образовательное учреждение высшего образования «Кубанский государственный университет физической культуры, спорта и туризма», 350015, Россия, Краснодарский край, г. Краснодар, ул. имени Буденного, дом 161, е-таil: Medvedeva-ol.an@mail.ru

Логинов Виктор Викторович - кандидат педагогических наук, доцент, Федеральное государственное бюджетное образовательное учреждение высшего образования «Уральский государственный университет физической культуры», 454091, Россия, 2. Челябинск, ул. Орджоникидзе, дом 1, e-mail: nata91-2012@mail.ru

DOI 10.14526/2070-4798-2018-13-3-143-149

УДК 796.07

ББК 75.1. 74.480.26

\title{
МОДЕЛЬ УПРАВЛЕНИЯ КАЧЕСТВОМ ПОДГОТОВКИ СТУДЕНТОВ В СФЕРЕ ФИЗИЧЕСКОЙ КУЛЬТУРЫ И СПОРТА В УСЛОВИЯХ ТРАНСДИСЦИПЛИНАРНОЙ ОБРАЗОВАТЕЛЬНОЙ СРЕДЫ
}

\author{
Жабаков В.Е. ${ }^{1}$, Жабакова Т.В. ${ }^{1}$, Коняхина Г.П. ${ }^{1}$ \\ ${ }^{1}$ ФГБОУ ВО «Южно-Уральский государственный гуманитарно-педагогический \\ университет», Россия, г. Челябинск, \\ gabakovvu@yandex.ru, zhabakova@inbox.ru,konyahinagp@cspu.ru
}

\begin{abstract}
Аннотация. Изменение сочииально-экономических условий подготовки студентов в сфере физической культуры и спорта в контексте смены существующих педагогических парадигм обусловливает изменение условий организации образовательной среды. Одним из способов решения этой проблемы является разработка новых стратегий управления качеством подготовки студентов вузов физической культуры, ориентированных на трансдисциплинарные методы и формы обучения. Материалы. В качестве компонентов модели управления качеством подготовки студентов в сфере физической культуры $и$ спорта в условиях трансдисциплинарной образовательной среды рассматриваем мотивационно-целевой, содержательно-процессуальный, организационно-методический, информационно-аналитический, самоактуализационный. Метод многомерных матрии позволяет объединить компоненты модели в единую трансдисциплинарную среду. Результаты применения метода могут быть представлены в виде классификации всех выбранных вариантов, кластеров информации, индивидуального маршрута освоения трансдисциплинарных знаний. Учитывая особенности организации управления качеством
\end{abstract}


подготовки студентов, нами выделень критерии эффективности реализации модели: автономность учебной деятельности, соотношение важности и уровня достижения компетенций, удовлетворенность организацией учебного процесса. Методы исследования Исследование автономности учебной деятельности осуществлялось при помощи опросника Г.С. Прыгина «Исследование автономности-зависимости личности в учебной деятельности». Критерий «важность формирования компетенций» изучался $c$ использованием модифицированной анкеты В.И. Байденко. Для изучения удовлетворенности организаџией учебного процесса использована модифицированная анкета Е.А. Лебедевой. Результаты. Внедрение модели управления качеством подготовки студентов в сфере физической культуры и спорта в условиях трансдисииплинарной образовательной средь обеспечивает переход от «знаниевой парадигмы» $к$ «компетентностно-ориентированной» 6 контексте совместных стратегий организации трансдисииплинарного процесса. Заключение. Концептуальная модель управления качеством подготовки студентов в сфере физической культуры и спорта в условиях трансдисичилинарной образовательной среды выступает как форма представления одного из «уровней» управления качеством. Реализаџия обобщённой модели в педагогической вузовской практике позволяет внести инновачионные компоненты в содержание и структуру управления качеством подготовки студентов. В трансдисциплинарной образовательной среде управление качеством подготовки студентов приобретает не только особую значимость, но и наполняется личностно-смысловым отночением к прочессу обучения.

Ключевые слова: подготовка студентов в сфере физической культуры и спорта, управление качеством, трансдисииплинарная образовательная среда.

Для цитирования: Жабаков В.Е., Жабакова Т.В., Коняхина Г.П. Модель управления качеством подготовки студентов в сфере физической культуры и спорта в условиях трансдисциплинарной образовательной среды. Педагогико-психологические и медикобиологические проблемы физической культурь и спорта. 2018; 13(3): 143-149. DOI 10.14526/2070-4798-2018-13-3-143-149.

\section{MODEL OF QUALITY CONTROL OVER TRAINING STUDENTS IN THE SPHERE OF PHYSICAL CULTURE AND SPORT IN TERMS OF TRANSDISCIPLINARY EDUCATIONAL ENVIRONMENT

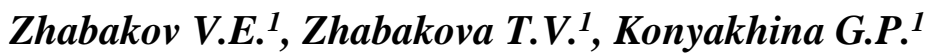 \\ ${ }^{1}$ Federal State Budgetary Educational Establishment of Higher Education "South-Ural State Humanitarian-Pedagogical University" \\ Russia,Chelyabinsk, gabakovvu@yandex.ru,zhabakova@inbox.ru, konyahinagp@cspu.ru}

Annotation. Social-economic conditions change of training students in the sphere of physical culture and sport in the context of the existing pedagogical paradigms change conditions changes in educational environment organization. One of the ways of this problem solution is new strategies creation of quality control over training physical culture higher educational establishment students, oriented at transdisciplinary methods and forms of teaching. Materials. We consider motivational-targeting, content-procedural, organizational-methodical, informationanalytical, self-actualization components as the components of quality control model over training students in the sphere of physical culture and sport in terms of transdisciplinary educational environment. Multidimensional matrix method helps to combine the components of the model into an integral transdisciplinary environment. The results of the method use can be presented in a form of all chosen variants classification, clusters of information, individual rout of transdisciplinary knowledge mastering. Taking into account the peculiarities of training quality control among students, we defined effectiveness criteria of the model realization: autonomy of educational 
activity, importance and the level of competences achievement ratio, satisfaction with educational process organization. Research methods: Autonomy of educational activity study was realized with the help of G.S. Prygin questionnaire "Autonomy-dependence study of a personality in educational activity". "The importance of competencies formation" criterion was studied using a modified V.I. Baydenko questionnaire. For satisfaction with educational process study a modified E.A. Lebedeva questionnaire was used. Results. The model introduction of quality control over training students in the sphere of physical culture and sport in terms of transdisciplinary educational environment provides transfer from "knowledge based paradigm" to "competence based" one in the context of modern strategies of transdisciplinary process organization. Conclusion. Conceptual model of quality control over training students in the sphere of physical culture and sport in terms of transdisciplinary educational environment fulfills the functions of one of the quality control "levels" presentation. The generalized model realization in pedagogical higher education practice helps to introduce innovative components into the content and structure of quality control over students training. In transdisciplinary educational environment students training quality control is not only very important, but it gains personal-notional attitude to educational process.

Keywords: training of students in the sphere of physical culture and sports, quality control, transdisciplinary educational environment.

For citations: Zhabakov V.E., Zhabakova T.V., Konayhina G.P. Model of quality control over training students in the sphere of physical culture and sport in terms of transdisciplinary educational environment. The Russian Journal of Physical Education and Sport (Pedagogico-Phycological and Medico-Biological Problems of Physical Culture and Sports). 2018; 13(3): 143-149. DOI 10.14526/2070-4798-2018-13-3-143-149.

\section{ВВЕДЕНИЕ}

Проблема

трансдисциплинарной

формирования образовательной среды является актуальной в контексте управления качеством, поскольку понятие «качество», охватывая все основные направления деятельности педагогического вуза от качества преподавания, подготовки и исследований до качества обучения, становится «ядром» трансдисциплинарности [1]. Поэтому центральными тенденциями обеспечения высокого уровня подготовки студентов в сфере физической культуры и спорта становятся «объединение» дисциплин в рамках общей методологической идеологии формирования трансдисциплинарной образовательной среды. Поэтому трансдисциплинарность можно рассматривать как методикотехнологическую основу организации педагогического управления качеством подготовки студентов в сфере физической культуры и спорта.

\section{МАТЕРИАЛЫ И МЕТОДЫ}

Содержательно-функциональная модель управления качеством подготовки студентов в сфере физической культуры и спорта в условиях трансдисциплинарной образовательной среды основана на интеграции понятий, организующих систему педагогического управления [2]. Структура данной модели построена на единстве и взаимосвязи составляющих ее структуру компонентов, уровней, стратегий, функций управления качеством. Эффективное управление качеством подготовки студентов в сфере физической культуры и спорта в условиях трансдисциплинарной образовательной среды обусловлено культурноисторическим представленным «педагогическая контекстом, понятиях «физическая культура».

Компоненты модели управления качеством подготовки студентов в сфере физической культуры и спорта в условиях трансдисциплинарной образовательной среды мы рассматриваем как относительно законченные элементы деятельности действия. В качестве компонентов модели управления качеством подготовки студентов в сфере физической культуры и спорта в условиях трансдисциплинарной образовательной среды рассматриваем 
мотивационно-целевой, содержательнопроцессуальный, методический, организационноинформационноаналитический, самоактуализационный.

Первый компонент -

мотивационно-целевой - включает функциональные цели управления качеством в условиях трансдисциплинарной образовательной среды. В трансдисциплинарной образовательной среде управление качеством подготовки студентов приобретает новое содержание, обеспечивая личностно-смысловое отношение к процессу обучения [3].

Организационно-методический

компонент модели управления качеством подготовки студентов в сфере физической культуры и спорта представлен подсистемой методов формирования трансдисциплинарной среды. В качестве одного из методов обучения, объединяющего дисциплины в единую трансдисциплинарную среду [1] мы использовали метод многомерных матриц, или метода морфологического ящика. Сущность метода морфологического анализа заключается в соединении в единую систему всех возможных «знаний, умений, владений», заложенных в предметах, объединенных в рамках трансдисциплинарной образовательной среды. Результаты применения метода могут быть представлены в виде классификации всех выбранных вариантов, кластеров информации, индивидуального маршрута освоения трансдисциплинарных знаний.

Информационно-аналитический компонент предполагает разработку системы критериев для оценки качества подготовки студентов. Оценка качества образования связана с пониманием цели (что достигается), процесса (условий для достижения цели), результата (меры достижения цели) образования. Результатом реализации информационноаналитического компонента модели стало выделение критериев эффективности модели управления качеством подготовки студентов в сфере физической культуры и спорта в условиях трансдисциплинарной образовательной среды. Учитывая особенности организации управления качеством подготовки студентов, мы выделили такие критерии, как автономность учебной деятельности, соотношение важности и уровня достижения компетенций, удовлетворенность организацией учебного процесса. Автономность учебной деятельности как критерий эффективности разработанной нами модели проявляется, во-первых, как потребность в самостоятельной разработке маршрута в процессе работы с многомерной матрицей, во-вторых, отражает мотивационную и когнитивную «окрашенность» организации образовательного процесса в условиях трансдисициплинарной образовательной среды, в-третьих, ориентирована на развитие субъектности личности студента. Исследование автономности учебной деятельности осуществлялось при помощи опросника Г.С. Прыгина «Исследование автономности-зависимости личности в учебной деятельности» [4].

Критерий «важность формирования компетенций» мы исследовали, опираясь на исследование В.И. Байденко [5], который предлагает оценить соотношение значимости и уровня достижений компетенций, исходя из 4 позиций: концентрация компетенций, низкий приоритет компетенций, избыточное напряжение, поддержание. Такая позиция позволяет нам обеспечить гибкость внедрения модели управления качеством подготовки студентов в сфере физической культуры и спорта в условиях трансдисциплинарной образовательной среды, поскольку ориентирована на выработку совместных стратегий организации трансдисциплинарного процесса.

Самоактуализационный компонент в управлении качеством подготовки студента в сфере физической культуры и спорта позволяет определить степень 
выраженность третьего критерия «удовлетворенность организацией учебного процесса», для исследования которого была использована модифицированная анкета Е.А. Лебедевой [6]. Удовлетворенность потребителей является в большей степени субъективным показателем, поскольку основывается на системе суждений относительно различных признаков образовательного процесса. Тесная связь экспектаций и удовлетворенности студентов организацией образовательного процесса оказывает влияние на мотивационную окрашенность процесса обучения, социально-психологические установки, определяющие мотивацию качества как общественную цель управления качеством подготовки студента в сфере физической культуры и спорта [2]. Для решения комплексной проблемы повышения качества подготовки студентов педагогического вуза в процессе формирования трансдисциплинарной образовательной среды конструирование трансдисциплинарности осуществлялось на основе таких дисциплин, как история физической культуры, теория и методика бодибилдинга и фитнеса, теория и методика спортивных и подвижных игр, теория и методика физической культуры, педагогическое физкультурно-спортивное совершенствование.

\section{РЕЗУЛЬТАТЫ}

\section{ИССЛЕДОВАНИЯ}

И ИХ ОБСУЖДЕНИЕ

Опытно-экспериментальная работа по внедрению модели управления качеством подготовки студентов в сфере физической культуры и спорта в условиях трансдисциплинарной образовательной среды проводилась с сентября 2017 по май 2018 г. на базе кафедры теории и методики физической культуры и спорта Высшей школы физической культуры и спорта Южно-Уральского государственного гуманитарно-педагогического

университета г. Челябинск. В исследовании приняли участие 120 человек в возрасте от 18 до 22 лет. Группы испытуемых $\quad$ (ЭГ-1, ЭГ-2, КГ $)$, участвующие в эксперименте, имели одинаковые начальные параметры.

После проведения формирующего этапа эксперимента наблюдается качественное изменение показателей по критерию «автономность учебной деятельности». В экспериментальных группах после применения метода многомерных матриц в контексте трансдисциплинарной образовательной среды изменилось количество «автономных» испытуемых по сравнению с констатирующим этапом эксперимента: ЭГ-1( $\varphi^{*}$ эмп $=3,46$ при $\varphi^{*}$ кр $=1,64(\rho \leq$ $0,05)$ и $\left.\varphi^{*} к р=2,31(\rho \leq 0,01)\right)$ и $Э Г-2$ $\left(\varphi^{*}\right.$ эмп $=2,74$ при $\varphi^{*}$ кр $=1,64(\rho \leq 0,05)$ и $\left.\varphi^{*} \kappa p=2,31(\rho \leq 0,01)\right)$. В КГ изменения не являются статистически значимыми $\left(\varphi^{*}\right.$ эмп $=1,42$ при $\varphi^{*}$ кр $=1,64(\rho \leq 0,05)$ и $\left.\varphi^{*} \kappa p=2,31(\rho \leq 0,01)\right)$. В процессе работы по многомерной матрице «автономные» студенты проявили в учебной деятельности большую настойчивость, развитый самоконтроль [4], самостоятельность, уверенность в себе.

Уровень

сформированности компетенций студентов в сфере физической культуры, несомненно, отражает «функциональную грамотность» [3], освоение образцов деятельности и требований к их качеству, однако критерий «важность» сформированности компетенций позволяет объединить субъективный опыт студента и целостность восприятия трансдисциплинарной ситуации обучения в процессе использования метода многомерных матриц. Изменение тенденцией к избыточному напряжению и низкому приоритету компетенций в экспериментальных группах является статистически значимым ЭГ-1( $\varphi^{*}$ эмп $=$ 2,82 при $\varphi^{*} \kappa р=1,64(\rho \leq 0,05)$ и $\varphi^{*} \kappa р=2,31$ $(\rho \leq 0,01))$ и ЭГ-2 $\left(\varphi^{*}\right.$ эмп $=2,78$ при $\varphi^{*} к р=$ $1,64(\rho \leq 0,05)$ и $\left.\varphi^{*} к р=2,31(\rho \leq 0,01)\right)$. В КГ изменения показателя низкий приоритет компетенций отмечено при $\rho \leq 0,05$ ( $\varphi^{*}$ эмп $=1,08$ при $\left.\varphi^{*} \kappa p=1,64\right)$. Увеличение в экспериментальных группах количества 
респондентов, отмечающих важность формирования компетенций по показателю «поддержка» (ЭГ-1 - на 22,5\%, и ЭГ-2 - на $22,2 \%)$, позволяют сделать вывод, что внедрение модели позволяет усилить воздействие на субъективный опыт студентов, поскольку важность достижения компетенций отражает личностный смысл системы получаемых знаний, умений, «владений».

Результаты

формирующего

эксперимента показывают изменение удовлетворенности студентов организацией образовательного процесса. Так, в КГ отмечено ЭГ-1 и ЭГ-2 при статистически значимом изменении высокого и низкого уровней отмечаются незначительные изменения среднего и достаточного уровней. В частности, в ЭГ-1 уменьшение количества испытуемых, показавших низкий уровень удовлетворенности организацией образовательного процесса, составило 40,7\%, в ЭГ-2 - 36\%. Изменение среднего и достаточного уровня в ЭГ-1 составило $7,4 \%$, в ЭГ-2 - 8\% и 4\%. Статистически значимые различия $(\rho \leq 0,01)$ по показателю «удовлетворенность организацией процесса обучения» выявлены между КГ и ЭГ-1 ( $\varphi^{*}{ }_{\text {эмп }}=3,08$, при $\varphi^{*}{ }_{\text {кр }}=1,64(\rho \leq 0,05)$ и 2,31 $\left.(\rho \leq 0,01)\right)$, КГ и ЭГ-2 ( $\varphi^{*}{ }_{\text {эмп }}=3,35$ при $\varphi^{*}$ кр $=1,64(\rho \leq$ $0,05)$ и 2,31 $(\rho \leq 0,01))$. Следовательно, следует признать значимость изменения критерия на формирующем этапе эксперимента.

Таким образом, введение метода многомерных матриц как формы реализации модели управления качеством подготовки студентов в сфере физической культуры и спорта в условиях трансдисциплинарной образовательной среды обеспечивает особую значимость субъектности образовательного процесса, обеспечивая переход от «знаниевой парадигмы» к «компетентностноориентированной».

\section{ЗАКЛЮЧЕНИЕ}

Концептуальная модель управления качеством подготовки студентов в сфере физической культуры и спорта в условиях трансдисциплинарной образовательной среды выступает как форма представления одного из «уровней» управления качеством. Реализация обобщённой модели в педагогической вузовской практике позволяет внести инновационные компоненты в содержание и структуру управления качеством подготовки студентов. В трансдисциплинарной образовательной среде управление качеством подготовки студентов приобретает не только особую значимость, но и наполняется личностно-смысловым отношением к процессу обучения.

\section{Список литературы}

1. Мокий В.С. Методология трансдисииплинарности. 3-е изд., испр. и допол. Нальчик: АНОИТТ. 2017: 112.

2. Жабаков В.Е. Педагогическое управление качеством подготовки специиалиста физической культуры: монография. Челябинск: Изд-во Челяб. Юж.-Урал. гос. гуман.-пед. ун-та. 2016: 237.

3. Ивлиева И.А., Панасюк В.П., Чернышева Е.К. Кониептуальные основы построения системь качества профессионального образования: монография. СПб.: Институт профтехобразования РАО. 2001: 152.
4. Реан
A.A.
Практическая психодиагностика личности. СПб.: Изд-во С.Петерб. ун-та. 2001: 56.

5. Байденко В.И. Выявление состава компетенций выпускников вузов как необходимый этап проектирования ГОС ВПО нового поколения: методическое пособие. М.: Исследовательский центр проблем качества подготовки специалистов. 2006: 72 .

6. Лебедева Е.А., Скок Г.Б. Управление качеством учебного процесса и деятельности преподавателя на основе удовлетворенности потребителей образовательных услуг. Университетское управление: практика и анализ. 2005; 1: 104-108.

7. Kuznetsova Z., Kuznetsov A., Mutaeva I., Khalikov G., Zakharova A., 2015. Athletes training based on a complex assessment of functional state. In Proceedings of the $3^{\text {rd }}$ International Congress on Sport Sciences Research and Technology support. SCITEPRESS. P. 156-160 (Scopus).

8. 14. Kuznetsov A., Mutaeva I., Kuznetsova Z., 2017. Diagnostics of Functional State and Reserve Capacity of young Athletes' Organism. In Proceedings of the $5^{\text {th }}$ International Congress on Sport Sciences Research and Technology support. SCITEPRESS. P. 111-115 (Scopus).

\section{References}


1. Moki, V. S. Methodology of transdisciplinarity-4 [Text] / V. S. Mokios. 3rd ed., ISPR. and extra. - Nalchik: ANOIT, 2017. - 112 p.

2. Zhabakov, V. E. Pedagogical quality management of specialists training in physical culture: monograph [Text] / V. E. Tabakov. - Chelyabinsk: publishing house of Chelyabinsk. South.-Ural. state human.- PED. UN-TA, 2016. - 237s.

3. Ivlieva, I. A. Conceptual bases of construction of system of quality of professional education: monograph. [Text] / A. I. Ivliev, V. P. Panasyuk, E. K. Chernysheva. - SPb. Institute of vocational education RAO, 2001. - 152 p.

4. Rean, A. A. Practical psychodiagnostics of personality [Text] / A. A. Rean. - SPb.: Izd-vo S.peterb. UN-TA, 2001. - 56 p.

5. Baydenko, V. I. Identification of set of competences of graduates as a necessary stage in the design of STATE VPO new generation [Text]: methodical manual / baidenko. - M.: Research center for the quality of training, 2006. - $72 \mathrm{p}$.

6. Lebedeva, E. A. management of quality of educational process and activity of the teacher on the basis of satisfaction of consumers of educational services[Text] / E. A. Lebedeva, G. B. Skok // University management: practice and analysis. - 2005. - No. 1. - 104-108 P.

7. Kuznetsova Z., Kuznetsov A., Mutaeva I., Khalikov G., Zakharova A., 2015. Athletes training based on a complex assessment of functional state. In Proceedings of the $3^{\text {rd }}$ International Congress on Sport Sciences Research and Technology support. SCITEPRESS. P. 156-160 (Scopus).

8. Kuznetsov A., Mutaeva I., Kuznetsova Z., 2017. Diagnostics of Functional State and Reserve Capacity of young Athletes' Organism. In Proceedings of the $5^{\text {th }}$ International Congress on Sport Sciences Research and Technology support. SCITEPRESS. P. 111-115 (Scopus).

\title{
Подано: 13.08.2018
}

Жабаков Владислав Ермекбаевич - кандидат педагогических наук, доцент, Высшая школа физической культуры и спорта, ФГБОУ ВО «Южно-Уральский государственный гуманитарно- педагогический университет», 454080, г. Челябинск, пр. Ленина, дом 69, email: gabakovvu@yandex.ru,_ORCID:0000-0003-0897-1840

Жабакова Татьяна Викторовна - кандидат педагогических наук, доцент кафедры педагогики и психологии, ФГБОУ ВО «Южно-Уральский государственный гуманитарнопедагогический университет», 454080, г. Челябинск, пр. Ленина, дом 69, e-mail: zhabakova@inbox.ru, ORCID: 0000-0001-9947-5505

Коняхина Галина Петровна - дочент кафедры теории и методики физической культуры и спорта, Высшая школа физической культуры и спорта, ФГБОУ ВО «Южно-Уральский государственный гуманитарно- педагогический университет», 454080, г. Челябинск, пр. Ленина, дом 69, e-mail:, konyahinagp@cspu.ru, ORCID:0000-0003-0132-3568

\author{
DOI 10.14526/2070-4798-2018-13-3-149-157 \\ УДК 574 \\ ББК 20.1
}

\section{МОДЕЛЬ РАЦИОНАЛЬНОГО ВЗАИМОДЕЙСТВИЯ ЧЕЛОВЕКА С ПРИРОДОЙ}

\author{
Колесник А.И. ${ }^{1}$ \\ ${ }^{1}$ ФГБОУ ВО «Ульяновский государственный педагогический университет имени И.Н. \\ Ульянова», Россия, г. Ульяновск, \\ anyakolesnik93@mail.ru
}

Аннотация. $K$ кониу XX века локальные экономические кризисы стали сменяться глобальным мировым кризисом, поставившим человеческое сообщество на грань выживания. Современная ичвилизаџия стоит перед угрозой исчезновения. Однако далеко не все люди готовы к осознанию данного факта, что свидетельствует о низком уровне 